Research Article

\title{
Kinetic Analysis of the Thermal Decomposition of Polymer-Bonded Explosive Based on PETN: Model-Fitting Method and Isoconversional Method
}

\author{
Trung Toan Nguyen, ${ }^{1}$ Duc Nhan Phan, ${ }^{1}$ Van Thom Do $\mathbb{D}^{,},{ }^{2}$ and Hoang Nam Nguyen $\mathbb{D}^{3}$ \\ ${ }^{1}$ Faculty of Special Equipment, Le Quy Don Technical University, 236 Hoang Quoc Viet, Ha Noi 100000, Vietnam \\ ${ }^{2}$ Faculty of Mechanical Engineering, Le Quy Don Technical University, 236 Hoang Quoc Viet, Hanoi 100000, Vietnam \\ ${ }^{3}$ Modeling Evolutionary Algorithms Simulation and Artificial Intelligence, Faculty of Electrical \& Electronics Engineering, \\ Ton Duc Thang University, Ho Chi Minh City, Vietnam
}

Correspondence should be addressed to Hoang Nam Nguyen; nguyenhoangnam@tdtu.edu.vn

Received 25 August 2019; Revised 30 May 2020; Accepted 17 June 2020; Published 11 July 2020

Academic Editor: Alain Portavoce

Copyright (c) 2020 Trung Toan Nguyen et al. This is an open access article distributed under the Creative Commons Attribution License, which permits unrestricted use, distribution, and reproduction in any medium, provided the original work is properly cited.

\begin{abstract}
This work investigates kinetics and thermal decomposition behaviors of pentaerythritol tetranitrate (PETN) and two polymerbonded explosive (PBX) samples created from PETN (named as PBX-PN-85 and PBX-PP-85) using the vacuum stability test (VST) and thermogravimetry (TG/DTG) techniques. Both model-free (isoconversional) and model-fitting methods were applied to determine the kinetic parameters of the thermal decomposition. It was found that kinetic parameters obtained by the modified Kissinger-Akahira-Sunose method (using non-isothermal TG/DTG data) were close to those obtained by the isoconversional and model-fitting methods that use isothermal VST data. The activation energy values of thermal decomposition reactions were 125.6-137.1, 137.3-144.9, and 143.9-152.4 kJ.mol ${ }^{-1}$ for PBX-PN-85, PETN, and PBX-PP-85, respectively. The results demonstrate the negative effect of the nitrocellulose-based binder in reducing the thermal stability of single PETN, while the polystyrene-based binder seemingly shows no adverse influence on the thermal decomposition of PETN in our presented PBX compositions.
\end{abstract}

\section{Introduction}

Pentaerythritol tetranitrate (also called PETN), which is a popular nitrate explosive, is extensively used in civilian and military applications due to its high energy characteristics $[1,2]$. The main drawback of PETN is that it is highly sensitive to impact and friction pulses, and thus there may be explosion risks in the processes of production, storage, and especially in the transportation of PETN. Therefore, PETN is often used in the form of a polymer-bonded explosive (also called PBX) [3-5] to overcome this shortcoming. The PBX sample based on PETN is a composite explosive in which the PETN particles are covered and bonded by the polymeric binder. The polymeric binder in PBX composition can reduce the sensitivity of explosive to mechanical pulses and make the charge compression easier and safer [6-9].
Like all other high-energy materials, the PBX composition is also an unstable thermodynamic system [10]. Compared to the single explosive such as PETN, the thermal decomposition of PBX is generally more complex because of the incompatible reactions between explosives and the polymeric binders [11-14], and the safety and performance of PBX sample may change during aging. Therefore, the behaviors and kinetics of thermal decomposition of PBX samples should be evaluated and clarified to assess the safety and the thermal hazard potential during storage. The decomposition kinetics and thermal behaviors of several composite explosives based on PETN have been carefully examined, and it was shown that the presence of the additive materials exerts powerful impacts on the thermal decomposition of these explosives [15-19]. 
In this study, we investigate the thermal decomposition kinetics of two PETN-based PBX samples named as PBXPN-85 and PBX-PP-85. These results were compared with those of a single PETN to evaluate the influence of binders on the thermal decomposition behaviors of explosives. Thermal analyses were conducted by thermogravimetry (TG/DTG) and vacuum stability test (VST), where the VST method (developed by STABIL, Czech Republic) is commonly used to examine the chemical stability, compatibility, and shelf-life of energetic materials in recent years $[10,14,20]$. Based on TG/DTG curves and VST results, we determined kinetic parameters by using isoconversional and model-fitting methods according to the ICTAC kinetics committee recommendations [21]. It is noteworthy that while model-fitting and isoconversional methods are both applicable to isothermal data, the model-fitting method is generally not applicable to non-isothermal techniques since the kinetic parameters obtained for non-isothermal data utilizing model-fitting technique are highly variable [22].

\section{Materials and Methods}

2.1. Materials. We imported Class-1 PETN with a melting temperature of over $139.0^{\circ} \mathrm{C}$ from South Korea. Good quality nitrocellulose (NC), that has a nitrogen content of $12.20 \%$, was supplied from the Vietnam factory. Polystyrene (PS), which has an average molecular weight of 80,000 $u$, was produced in our laboratory. The widely used plasticizer, dioctyl phthalate (DOP), was utilized to make the binder from the PS and NC (the ratios of DOP/NC and DOP/PS were $3 / 1$ and $2 / 1$, respectively). Besides, some suitable solvents such as toluene and ethyl acetate are used in this study.

\subsection{Experimental Techniques and Methods}

2.2.1. Preparation of PBX Samples. PS and NC were plasticized by DOP (the ratios of DOP/NC and DOP/PS are 3/1 and $2 / 1$, respectively), then dissolved in the suitable solvents (toluene for PS and ethyl acetate for NC), maintaining the polymer/solvent ratio of $1 / 15(\mathrm{w} / \mathrm{v})$, and kept for approximately 5 hours to obtain a homogeneous solution. The sample preparation method was carried out by mixing PETN crystals with the binders based on PS and NC. The mixing process took place on the heating device at $70^{\circ} \mathrm{C}$ for 30 minutes, and the PETN crystals were covered by the binder layers $[6,23]$. After that, the mixtures were vacuum-dried at 60 to $70^{\circ} \mathrm{C}$ for 5 hours to remove the solvents. Table 1 shows the compositions of two proposed PBX samples.

2.2.2. Experimental Techniques. The thermal decomposition behaviors of PBX samples were determined by employing thermogravimetry (TG/DTG) and vacuum stability test (VST). The experimental conditions are as follows.

TG/DTG analysis was conducted using a NETZSCH STA 409 PC/PG (NETZSCH-Gerätebau GmbH, Selb, Germany). PBX samples (around $5.0 \mathrm{mg}$ ) were put in an aluminum oxide crucible and heated at various heating rates
TABLE 1: The composition of two PBX samples based on PETN.

\begin{tabular}{lcccc}
\hline \multirow{2}{*}{ Composition } & \multicolumn{4}{c}{ Content of materials (wt\%) } \\
& PETN & DOP & PS & NC \\
\hline PBX-PP & 85.00 & 10.00 & 5.00 & - \\
PBX-PN & 85.00 & 11.25 & - & 3.75 \\
\hline
\end{tabular}

of $3,5,7$, and $10 \mathrm{~K} \cdot \mathrm{min}^{-1}$. The sample vial was heated from 30 to $350^{\circ} \mathrm{C}$. Experimental heating processes were carried on under a dynamic nitrogen atmosphere with a flow rate of $30 \mathrm{~mL} \cdot \mathrm{min}^{-1}$.

The VST test was carried out in a STABIL apparatus (OZM Research, Pardubice, Czech Republic). During this test, PBX samples were heated isothermally at different temperatures of $135,140,145$, and $150^{\circ} \mathrm{C}$ under vacuum pressure (at most $0.672 \mathrm{kPa}$ ). A pressure sensor and a computer are used to record the relationship of the released gas volume versus heating time. The sample mass was $20.0 \mathrm{mg}$, and we performed the test from 5 to 10 days (depending on the temperature test), until the end of the thermal decomposition reaction.

2.2.3. Kinetics Analysis. The kinetics of thermal decomposition reactions in solids can be expressed as the following equation:

$$
\frac{\mathrm{d} \varphi}{\mathrm{d} t}=k(T) \cdot c(\varphi)
$$

where $t$ is time (s); $\varphi$ is the extent of conversion; $T$ is the temperature $(\mathrm{K})$; and $k(T)$ is a function of conversion representing the reaction model. For the TG tests, the extent of conversion $\varphi$ is defined as follows:

$$
\varphi_{t}=\frac{m_{i}-m_{t}}{m_{i}-m_{f}}
$$

where $m_{i}, m_{t}$, and $m_{f}$ are the initial sample mass, sample mass at any time $t$, and sample mass at the end of the decomposition, respectively. For the VST test, the value of $\varphi$ is expressed as $[13,24]$

$$
\varphi_{t}=\frac{p_{t}-p_{0}}{p_{\max }-p_{0}}
$$

where $p_{\max }$ is the pressure at the end of decomposition, $p_{t}$ is the pressure at any time $t$, and $p_{0}$ is initial pressure. Following the Arrhenius equation, $k(T)$ is computed by

$$
k(T)=A \cdot e^{-E / \mathrm{RT}},
$$

where $R, T, E$, and $A$ are the universal gas constant, absolute temperature, activation energy, and pre-exponential factor, respectively.

(1) Model-Fitting Method. Model-fitting methods employed different forms of reaction model for finding the referred decomposition kinetic parameters; some of these reaction models are illustrated in Table 2.

For isothermal conditions, equation (1) can be used in the integral form as follows [22, 24]: 
TABLe 2: Different reaction models generally applied to describe the thermal decomposition in solids $[21,22,24,25]$.

\begin{tabular}{lccc}
\hline Model no. & Reaction model & $c(\varphi)$ & $i(\varphi)$ \\
\hline 1 & Avarami-Erofe'ev (A2) & $2(1-\varphi)[-\ln (1-\varphi)]^{1 / 2}$ & {$[-\ln (1-\varphi)]^{1 / 2}$} \\
2 & Avarami-Erofe'ev (A3) & $3(1-\varphi)[-\ln (1-\varphi)]^{2 / 3}$ & {$[-\ln (1-\varphi)]^{1 / 3}$} \\
3 & Avarami-Erofe'ev (A4) & $4(1-\varphi)[-\ln (1-\varphi)]^{3 / 4}$ & {$[-\ln (1-\varphi)]^{1 / 4}$} \\
4 & Power law (P2) & $2 \varphi^{(1 / 2)}$ & $\varphi^{(1 / 2)}$ \\
5 & Power law (P3) & $3 \varphi^{(2 / 3)}$ & $\varphi^{(1 / 3)}$ \\
6 & Power law (P4) & $4 \varphi^{(3 / 4)}$ & $\varphi^{2}$ \\
7 & 1-D diffusion (D1) & $1 /(2 \varphi)$ & {$[(1-\varphi) \ln (1-\varphi)]+\varphi$} \\
8 & 2-D diffusion (D2) & {$\left[1-(1-\varphi)^{1 / 3}\right]^{2}$} \\
9 & 3-D diffusion-Jander (D3) & $-\ln (1-\varphi)$ & $(1-\varphi)^{-1}-1$ \\
10 & First-order (F1) & $(1-\varphi)$ & {$\left[(1-\varphi)^{-2}-1\right] / 2$} \\
11 & Second-order (F2) & $(1-\varphi)^{2}$ & $\left.(1-\varphi)^{1 / 2}\right]$ \\
12 & Third-order (F3) & $(1-\varphi)^{3}$ & {$\left[1-(1-\varphi)^{1 / 3}\right]$} \\
13 & Contracting area (R2) & $2(1-\varphi)^{1 / 2}$ & $3(1-\varphi)^{2 / 3}$ \\
14 & Contracting volume (R3) & & $\left.[1-\varphi)^{2 / 3}\right] / 2\left[1-(1-\varphi)^{1 / 3}\right]$ \\
\hline
\end{tabular}

$$
i(\varphi)=\int_{0}^{\varphi}[c(\varphi)]^{-1} \mathrm{~d} \varphi=k(T) t,
$$

where $i(\varphi)$ is the integrated form of the reaction model $c(\varphi)$. Replacing each reaction model from Table 1 into equation (5), the rate constant can be computed from the slope of the straight line when plotting $i(\varphi)$ against $t$. Then, we can base on $i(\varphi)$ and $c(\varphi)$ formulations in the reaction model to determine $k(T)$. For each selected reaction model, $k(T)$ is determined at different temperatures, and the kinetic parameters can be calculated by the Arrhenius equation:

$$
\ln k(T)=\ln A-\left(\frac{E}{R T}\right) \text {. }
$$

(2) Isoconversional (Model-Free) Method. The reaction model (as in equation (1)) in the isoconversional method is considered as being independent of temperature. Under the isothermal condition of the VST test, combining equations (4) and (5), we obtain $[13,22,24]$

$$
-\ln t_{\varphi, j}=\ln \left[\frac{A}{i(\varphi)}\right]-\frac{E_{\varphi}}{R T_{j}},
$$

where the activation energy $\left(E_{\varphi}\right)$ is estimated from the slope of the straight line when plotting $\left(-\operatorname{lnt}_{\varphi, j}\right)$ against $\left(1 / T_{j}\right)$. Thus, the dependencies of activation energy $\left(E_{\varphi}\right)$ on the conversion of the thermal decomposition $(\varphi)$ could be obtained.

At a linear heating rate $\beta=\mathrm{d} T / \mathrm{d} t$ and under non-isothermal condition, equation (1) can be described as the following:

$$
\frac{\mathrm{d} \varphi}{\mathrm{d} t}=\beta \frac{\mathrm{d} \varphi}{\mathrm{d} T}=A e^{-E / R T} c(\varphi),
$$

and Kissinger, Akahira, and Sunose introduced the modelfree method using the following linear equation $[22,26]$ :

$$
\ln \left(\frac{\beta_{k}}{T_{\varphi, k}^{2}}\right)=\ln \left(\frac{A R}{i(\varphi) E_{\varphi}}\right)-\frac{E_{\varphi}}{R T_{\varphi}} .
$$

For each extent of conversion $\varphi$, the values of $E$ and $A$ can be found from the slope and the intercept when plotting $\ln \left(\beta / T^{2}\right)$ against $1 / T$. The function $i(\varphi)$ can be determined according to the methodology reported in the literature $[27,28]$.

\section{Results and Discussions}

3.1. The TG/DTG Results. TG/DTG curves of PETN, PBXPN-85, and PBX-PP-85 at different heating rates (i.e., 3, 5, 7 , and $10 \mathrm{~K} \cdot \mathrm{min}^{-1}$ ) were recorded and are shown in Figure 1.

For comparison, the characteristic parameters of TG/DTG curves of PETN, PBX-PN-85, and PBX-PP-85 are summarized in Table 3.

It has been shown that only a single decomposition step is related to the thermal decomposition of a single PETN (i.e., one-step reaction model) in all samples. The peak temperatures in DTG curves for the thermal decomposition of PETN, PBX-PN-85, and PBX-PP-85 were observed in a range of $186-201,183-199$, and $189-204^{\circ} \mathrm{C}$, respectively. Generally, the decomposition residue of all samples increases with the increasing heating rate, and the residue mass of PBX-PN-85 and PBX-PP-85 may be less than that of PETN because of the presence of inert ingredient (i.e., DOP and PS) in their formulation.

As seen, the thermal decomposition of PETN occurred at a higher temperature than PBX-PN-85 but lower than that of PBX-PP-85. DTG curves in Figure 1 also demonstrated the role of the binder on the thermal decomposition behaviors of PETN. Thermal stability and decomposition temperature of single PETN are clearly affected by the binders. Specifically, the energetic binder (i.e., NC-based binder) reduces the decomposition temperature of single PETN, while the nonenergetic binder (i.e., PS-based binder) hardly affects the thermal stability of PETN. Interestingly, the PBX-PN-85 sample also shows an early decomposition. This may be caused by the exothermic decomposition effect of $\mathrm{NC}$ and the release of the gaseous products in the early decomposition of PETN in the binder matrix [13]. Contrarily, the decomposition temperature of PBX-PP-85 has a slight increase because this PBX sample has less amount of PETN (compared to single PETN) in its composition [8].

According to equation (2), the corresponding curve of the conversion $\varphi$ versus temperature $T$ was obtained and is 


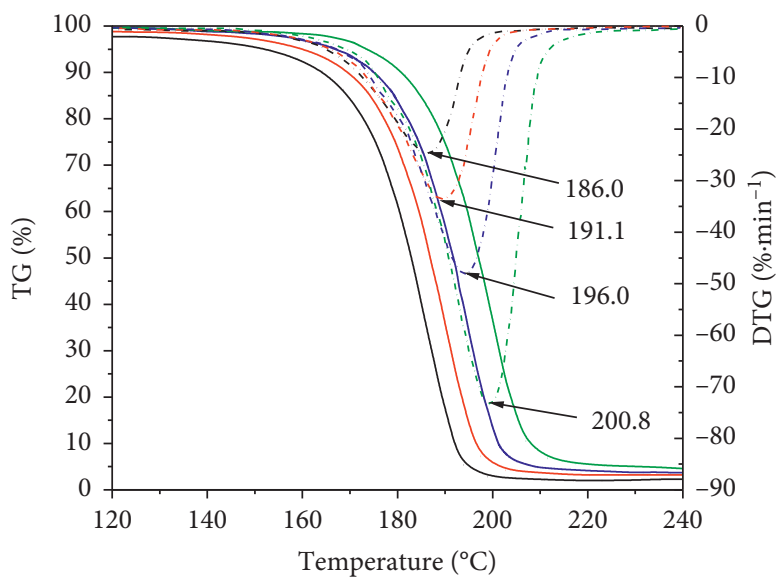

PETN

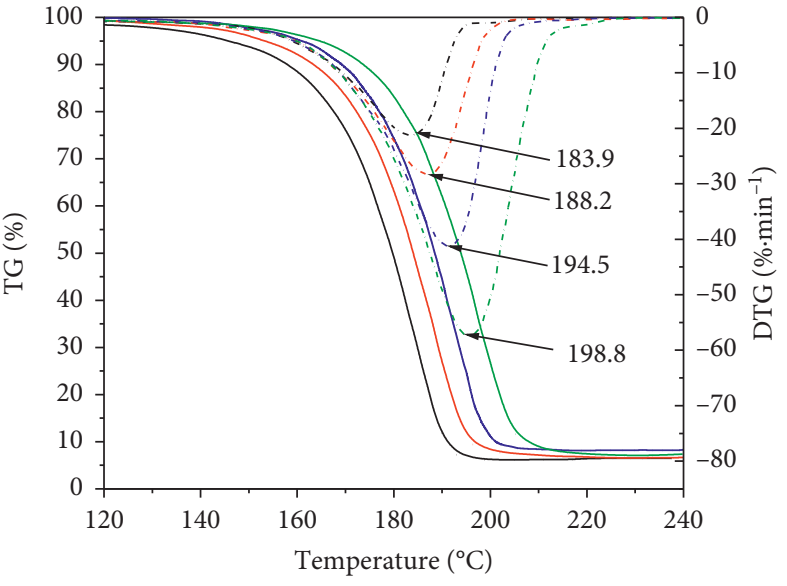

PBX-PN-85
$-7 \mathrm{~K} \cdot \mathrm{min}^{-1}$

$10 \mathrm{~K} \cdot \mathrm{min}^{-1}$

$3 \mathrm{~K} \cdot \mathrm{min}^{-1}$

$-7 \mathrm{~K} \cdot \mathrm{min}^{-1}$

(a)

(b)

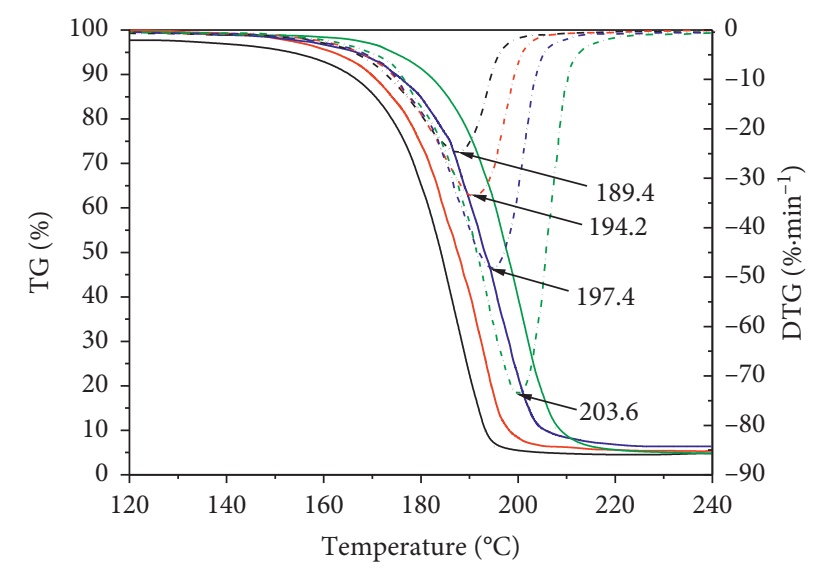

PBX-PP-85

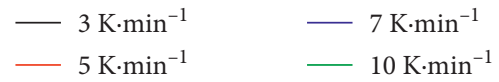

(c)

Figure 1: TG/DTG curves of PETN, PBX-PN-85, and PBX-PP-85 at several heating rates.

TABle 3: Kinetic parameters from TG/DTG data of PBX-PN-85, PBX-PP-85, and PETN.

\begin{tabular}{|c|c|c|c|c|c|c|}
\hline \multirow{2}{*}{ Material } & \multirow{2}{*}{$\beta\left(\mathrm{K} \cdot \min ^{-1}\right)$} & \multicolumn{5}{|c|}{ TG/DTG curve } \\
\hline & & $T_{\mathrm{ot}}\left({ }^{\circ} \mathrm{C}\right)$ & $T_{i}\left({ }^{\circ} \mathrm{C}\right)$ & $T_{p}\left({ }^{\circ} \mathrm{C}\right)$ & Mass loss (\%) & Residue (\%) \\
\hline \multirow{4}{*}{ PETN } & 3.0 & 165.5 & 130.2 & 186.0 & 98.3 & 1.7 \\
\hline & 5.0 & 169.6 & 132.0 & 191.1 & 97.2 & 2.8 \\
\hline & 7.0 & 172.7 & 133.2 & 196.0 & 96.3 & 3.7 \\
\hline & 10.0 & 178.9 & 135.6 & 200.8 & 96.0 & 4.0 \\
\hline \multirow{4}{*}{ PBX-PN-85 } & 3.0 & 162.3 & 127.1 & 183.9 & 95.3 & 4.7 \\
\hline & 5.0 & 166.8 & 129.8 & 188.2 & 94.4 & 5.6 \\
\hline & 7.0 & 169.0 & 130.9 & 194.5 & 94.0 & 6.0 \\
\hline & 10.0 & 175.3 & 133.5 & 198.8 & 93.1 & 6.9 \\
\hline \multirow{4}{*}{ PBX-PP-85 } & 3.0 & 168.6 & 136.2 & 189.4 & 93.7 & 6.3 \\
\hline & 5.0 & 172.5 & 138.0 & 194.2 & 93.1 & 6.9 \\
\hline & 7.0 & 177.0 & 139.9 & 197.4 & 91.5 & 8.5 \\
\hline & 10.0 & 183.2 & 142.5 & 203.6 & 91.9 & 8.1 \\
\hline
\end{tabular}

$T_{\mathrm{ot}}-$ onset temperature of decomposition exotherm peak, $T_{i}-$ the initial temperature of the mass loss, and $T_{p}$-the peak temperature of the DTG curve. 

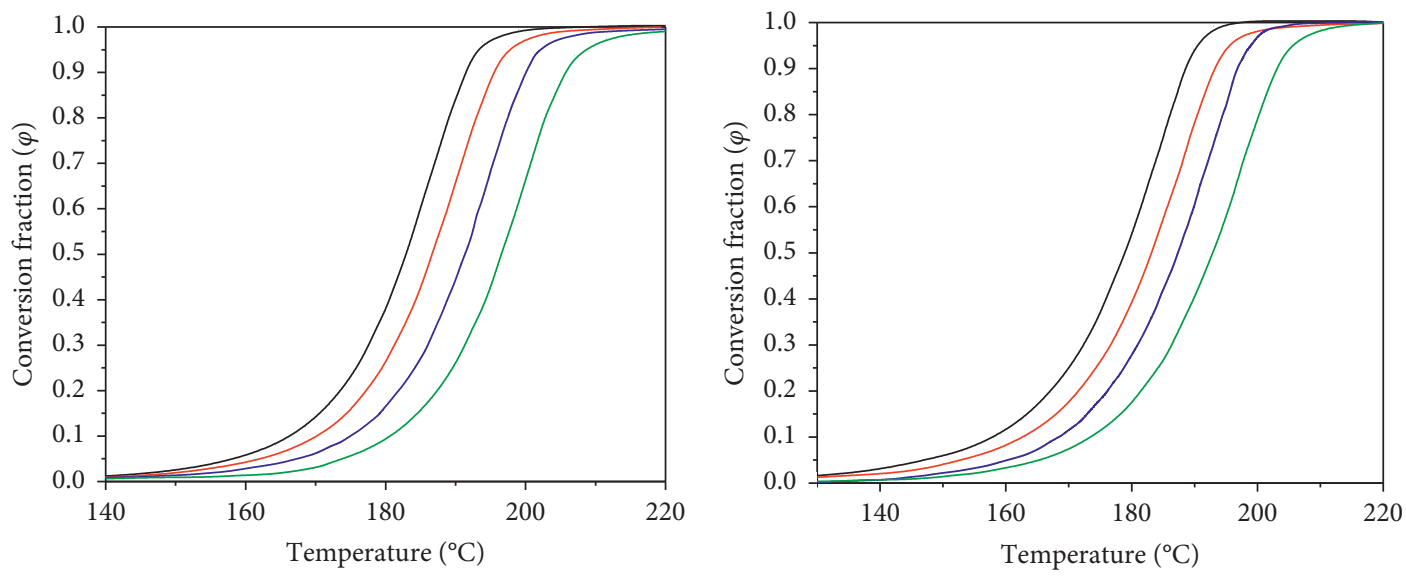

PETN

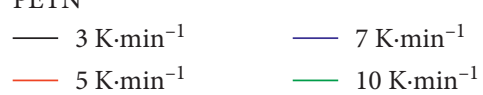

(a)
PBX-PN-85

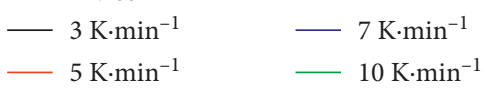

(b)

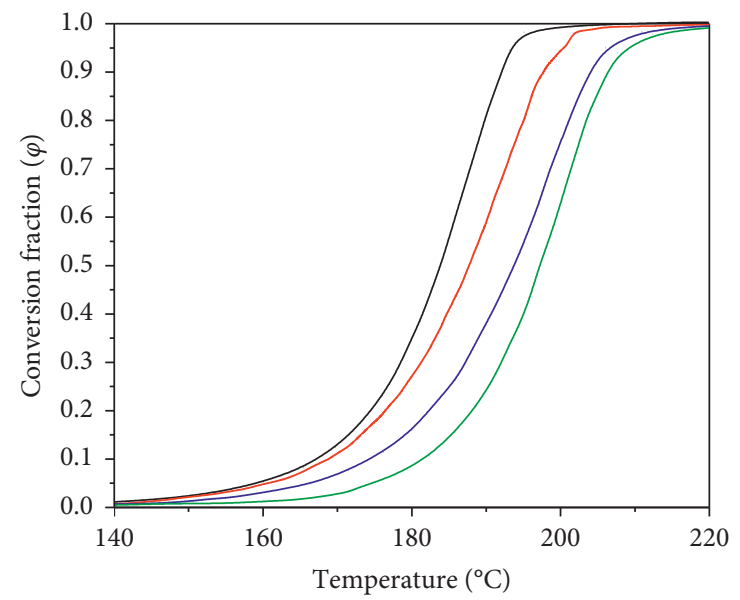

PBX-PP-85

$3 \mathrm{~K} \cdot \mathrm{min}^{-1}$
$-5 \mathrm{~K} \cdot \mathrm{min}^{-1}$

$-7 \mathrm{~K} \cdot \mathrm{min}^{-1}$

$10 \mathrm{~K} \cdot \mathrm{min}^{-1}$

(c)

Figure 2: $\varphi$ versus T curves of PETN, PBX-PN-85, and PBX-PP-85 at several heating rates.

presented in Figure 2. It can be observed that all of the $\varphi-T$ curves have the form of the sigmoid function (i.e., the " $S$ " shape curve), which is often obtained in the thermal analysis of high energetic material [29].

As recommended by the ICTAC kinetics committee $[21,30]$, the modified Kissinger-Akahira-Sunose (KAS) technique was applied for investigating the relationship between the activation energy and the conversion fraction. The fitting lines at each conversion fraction are presented in Figure 3 by plotting $\ln \left(\beta / T^{2}\right)$ against $1 / T$.

The activation energy $E_{\varphi}$ and the pre-exponential factor $A$ of the thermal decomposition of all samples were evaluated based on the slopes and intercepts of the plots shown in Figure 3 and are expressed in Table 4. The dependence of activation energy on the conversion by the modified KAS method is shown in Figure 4.
The mean activation energy $\left(E_{\varphi}\right)$ values (calculated according to the modified KAS method with the conversion range of $0.3-0.7[13,16])$ of single PETN, PBX-PN-85, and PBX-PP-85 are $144.9,137.1$, and $152.4 \mathrm{~kJ} \cdot \mathrm{mol}^{-1}$, respectively.

To verify these results obtained by the KAS method, the kinetic parameters were recalculated using NETZSCH Thermokinetic software according to the ASTM E698 [31]. The $E_{\varphi}$ values of single PETN, PBX-PN-85, and PBXPP-85 are $138.2,129.7$, and $150.9 \mathrm{~kJ} \cdot \mathrm{mol}^{-1}$, respectively. The results were close to those obtained from the KAS method with the maximum difference of approximately $5 \%$, which indicates the accuracy and reliability of measurements.

Compared to single PETN, the introduction of NC in PBX-PN-85 formulation leads to the decrease of its 


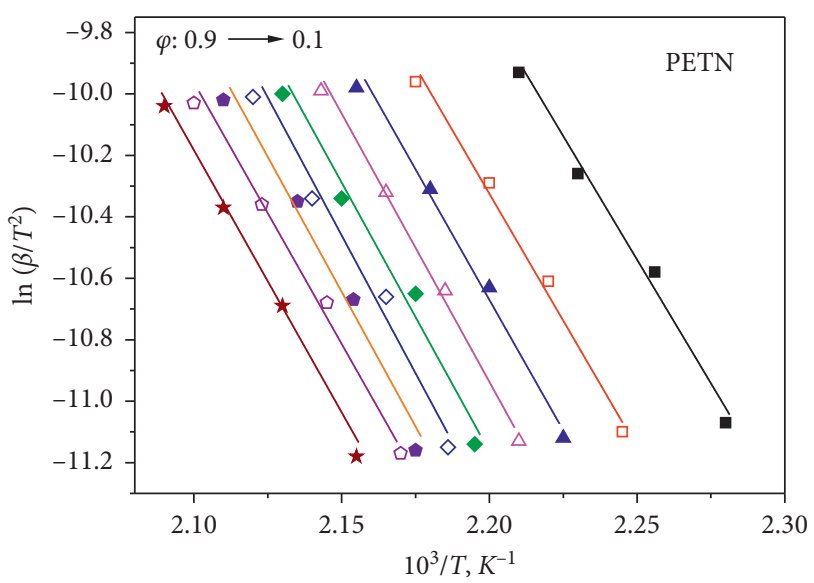

(a)

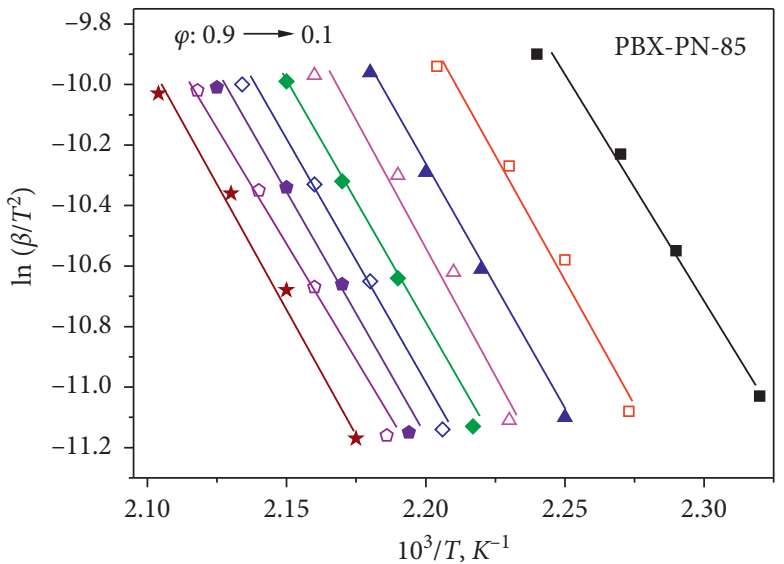

(b)

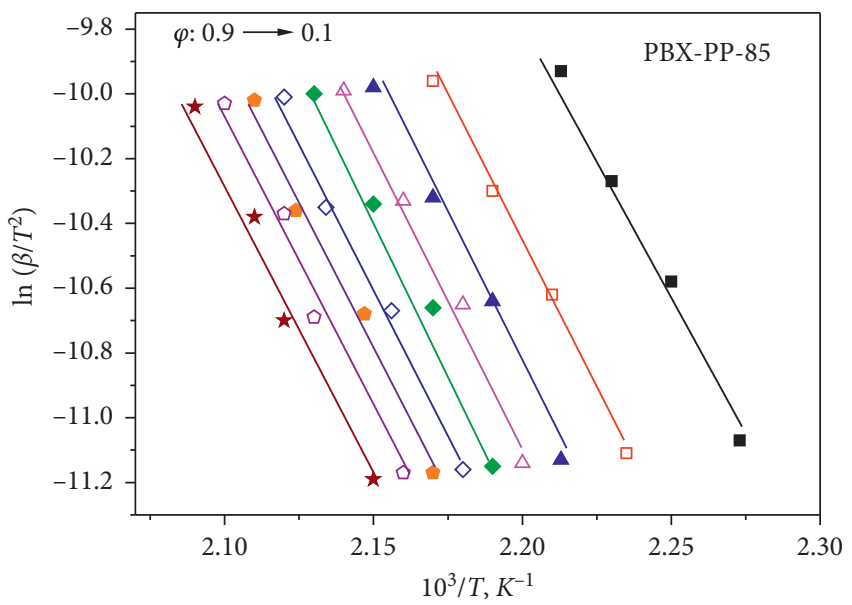

(c)

Figure 3: Isoconversional plots at selected conversion degree of PETN, PBX-PN-85, and PBX-PP-85 according to the modified KAS method.

TABLE 4: Kinetic parameters of PETN and PBXs by the modified KAS method.

\begin{tabular}{|c|c|c|c|c|c|c|c|c|c|}
\hline \multirow[b]{2}{*}{$\varphi$} & \multicolumn{3}{|c|}{ PETN } & \multicolumn{3}{|c|}{ PBX-PN-85 } & \multicolumn{3}{|c|}{ PBX-PP-85 } \\
\hline & $E_{\varphi}\left(\mathrm{kJ} \cdot \mathrm{mol}^{-1}\right)$ & $\ln A,\left(\min ^{-1}\right)$ & $R^{2}$ & $E_{\varphi}\left(\mathrm{kJ} \cdot \mathrm{mol}^{-1}\right)$ & $\ln A,\left(\min ^{-1}\right)$ & $R^{2}$ & $E_{\varphi}\left(\mathrm{kJ} \cdot \mathrm{mol}^{-1}\right)$ & $\ln A,\left(\min ^{-1}\right)$ & $R^{2}$ \\
\hline 0.1 & 133.8 & 24.7 & 0.9955 & 124.5 & 21.3 & 0.9835 & 139.3 & 27.8 & 0.9880 \\
\hline 0.2 & 138.3 & 26.3 & 0.9915 & 136.3 & 25.4 & 0.9905 & 150.4 & 32.5 & 0.9950 \\
\hline 0.3 & 141.3 & 27.2 & 0.9850 & 136.5 & 24.9 & 0.9945 & 152.6 & 33.2 & 0.9915 \\
\hline 0.4 & 145.2 & 28.4 & 0.9884 & 138.6 & 26.8 & 0.9964 & 152.1 & 32.4 & 0.9835 \\
\hline 0.5 & 145.3 & 28.6 & 0.9935 & 137.9 & 24.8 & 0.9924 & 155.5 & 34.1 & 0.9980 \\
\hline 0.6 & 147.1 & 29.9 & 0.9828 & 136.6 & 24.6 & 0.9920 & 153.2 & 32.2 & 0.9909 \\
\hline 0.7 & 145.8 & 28.9 & 0.9845 & 135.8 & 24.7 & 0.9960 & 148.5 & 31.3 & 0.9945 \\
\hline 0.8 & 141.4 & 27.5 & 0.9899 & 137.9 & 26.4 & 0.9949 & 147.6 & 29.8 & 0.9952 \\
\hline 0.9 & 141.8 & 27.7 & 0.9854 & 127.2 & 22.6 & 0.9935 & 146.7 & 27.8 & 0.9960 \\
\hline Mean & 144.9 & 28.6 & & 137.1 & 25.2 & & 152.4 & 32.6 & \\
\hline
\end{tabular}

activation energy because the thermal stability of the nitrate group in NC is less than that in PETN $[32,33]$. For PBXPP-85 formulation, besides the reducing mechanical sensitivity of the explosive, an inert binder system (i.e., DOP/ PS) acts as a stabilizer by trapping the active thermal decomposition product $[29,34]$, resulting in the higher activation energy and thus higher stability versus single PETN.
3.2. The VST Results. Results of TG/DTG were verified by VST studies, which were conducted at several isothermal temperatures (e.g., 125, 130, 135, and $140^{\circ} \mathrm{C}$ ). From the relationship of the volume of released gas versus heating time in VST tests, the conversion fraction values $(\varphi)$ for each time $(t)$ were computed according to equation (3), and the curve of the conversion fraction $(\varphi)$ versus heating time $(t)$ is plotted for all samples in Figure 5. 


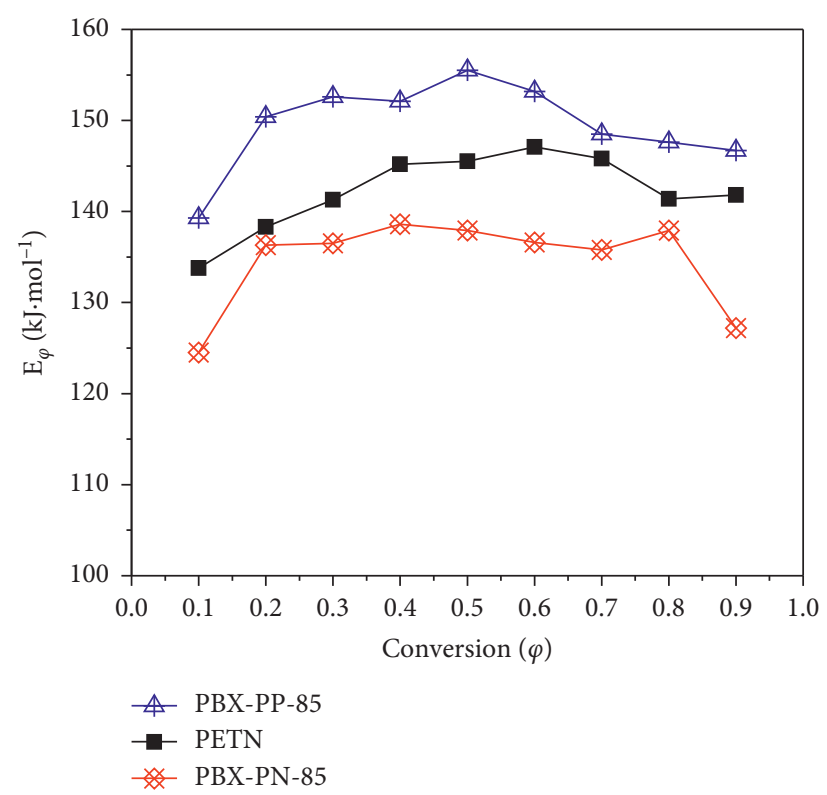

FIgURE 4: The dependence of activation energy on the conversion by the modified KAS method.

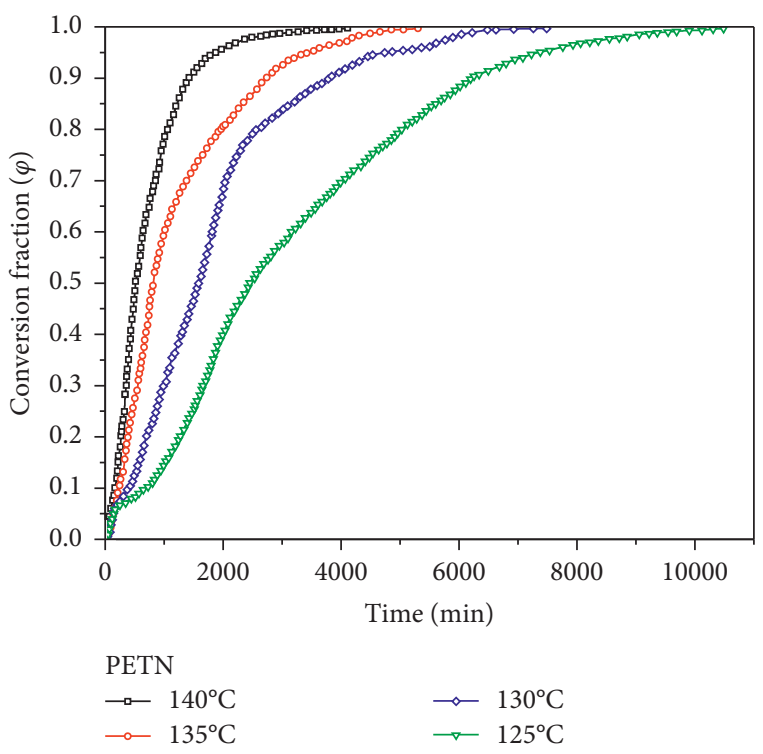

(a)

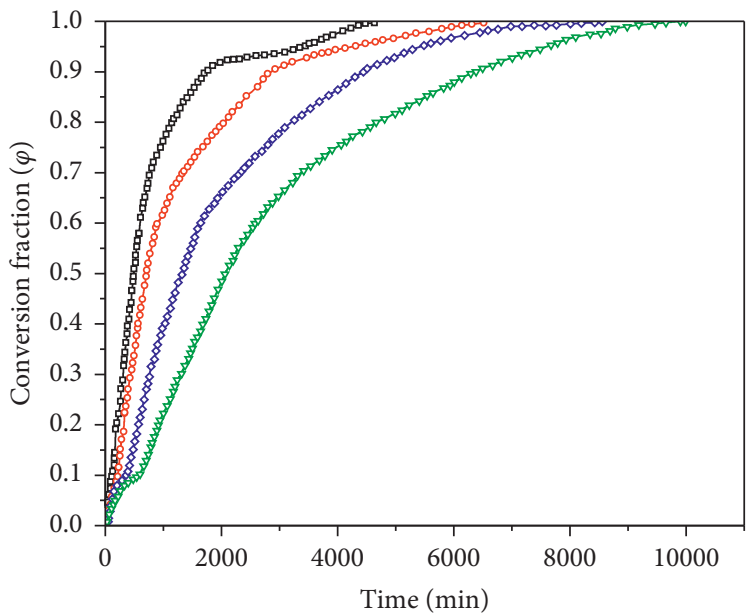

PBX-PN-85

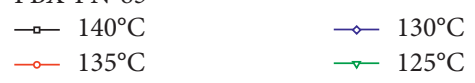

(b)

Figure 5: Continued. 

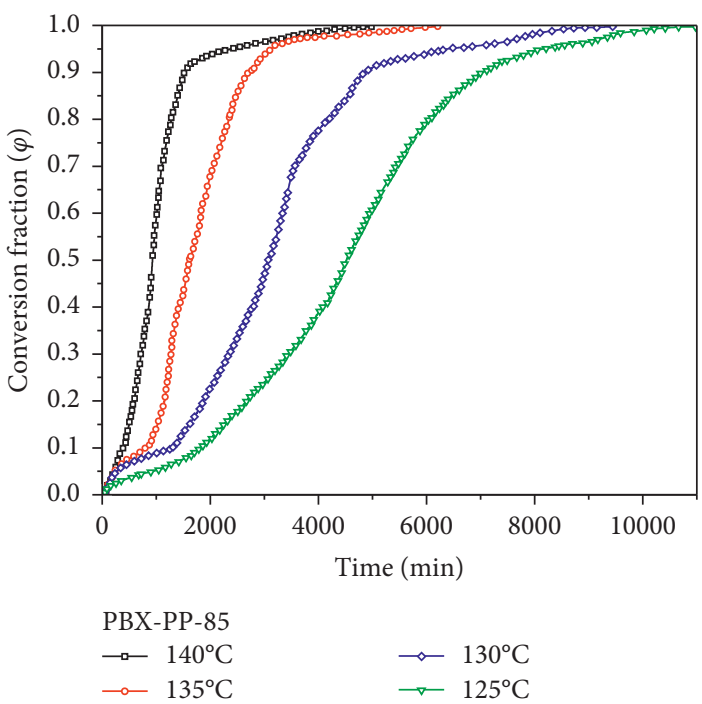

(c)

FIGURE 5: Conversion fractions $(\varphi)$ versus heating time $t$ for PBX-PN-85, PBX-PP-85, and PETN.

It is obvious from Figure 5 that the obtained $\varphi-t$ curves of PBX-PN-85, PBX-PP-85, and PETN obey the logarithmic trend, and the decomposition rate of all samples increased when the temperature was increased. In the case of PBX-PN85 and PETN, it is apparent that the conversion grew rapidly during the first 2000 minutes and the conversion rate is low in the next 8000 minutes until the samples were completely decomposed. Similarly, the conversion rate of PBX-PP-85 can also be derived from Figure 5. In the case of PBX-PP-85, the conversion also increased rapidly in the first 2000 minutes at 135 and $140^{\circ} \mathrm{C}$, while the conversion took longer time when tested at 125 and $130^{\circ} \mathrm{C}$. By comparing the results of all samples, it was found that PBX-PP-85 sample took a longer time for completing the conversion than PBX-PN-85 and PETN samples. For example, at an isothermal temperature $125^{\circ} \mathrm{C}$, the time for completing the conversion of PBX-PN-85, PETN, and PBX-PP-85 was 9990, 10485, and $10970 \mathrm{~min}$, respectively. The differences in the thermal stability of three samples were assessed by the activation energy employing the model-free (isoconversional) and model-fitting methods.

3.2.1. Isothermal Isoconversional Method from VST Data. Next, we utilize VST data to find kinetics parameters of PBX samples. By drawing $-\ln (t)$ versus $1 / T$ curve at each temperature according to equation (7) for each conversion $\varphi$, the kinetic thermal decomposition parameters of three samples were calculated and are expressed in Table 5. The dependence of activation energy on the conversion is presented in Figure 6.

These $E_{\varphi}$ values are in the same range of the $E_{\varphi}$ values calculated from TG/DTG data using the modified KAS method, thus demonstrating the reliability of the VST test in evaluating the $E_{\varphi}$ values of studied samples by the isothermal isoconversional method. The $E_{\varphi}$ values of PETN, PBX-PN-
85, and PBX-PP-85 were $137.3,129.7$, and $143.9 \mathrm{~kJ} \cdot \mathrm{mol}^{-1}$, respectively. Besides that, the $\ln (A)$ values of PETN, PBX$\mathrm{PN}-85$, and PBX-PP-85 were $31.9,28.0$, and $35.0 \mathrm{~min}^{-1}$, respectively.

3.2.2. Isothermal Model-Fitting Method from VST Data. The model-fitting method includes two fits: the first fit for determination of the model rate constant $k(T)$ that best fits the VST data and the second fit for determination of several kinetic parameters such as pre-exponential factor $A$ from the Arrhenius equation and the activation energy $E_{\varphi}[13,22]$. Fourteen reaction models from Table 1 were selected for fitting the conversion of the thermal decomposition. Table 6 shows the results for the pre-exponential factor, the activation energy, and squares of the correlation coefficients obtained by plotting the integrated form $i(\varphi)$ versus heating time $t$ at each isothermal temperature.

From Table 6, it was observed that the kinetic parameters (specifically, pre-exponential factor and activation energy), which are derived from the VST data utilizing the model-fitting method, are essentially independent of the reaction model used. It means that there is an insignificant difference between the kinetic parameters (i.e., $E_{\varphi}$ and $A$ ) calculated using different model reactions. For selecting the best model fitting, the correlation coefficient $R^{2}$ was used as a parameter. It was found that the best model that describes the thermal decomposition of PETN is contracting volume (R3) and the best model for PBX-PN-85 is 3-D diffusion-Jander (D3) while the best model for PBX-PP-85 is second-order (F2).

On the other hand, we found that the activation energy values calculated by the isothermal isoconversional method are approximate to those derived from the isothermal model-fitting method using the VST technique. To make a 
TABLE 5: Kinetic parameter of PETN and PBXs by the isothermal isoconversional method.

\begin{tabular}{lccccccrrr}
\hline & \multicolumn{3}{c}{ PETN } & \multicolumn{3}{c}{ PBX-PN-85 } & \multicolumn{3}{c}{ PBX-PP-85 } \\
& $E_{\varphi}\left(\mathrm{kJ} \cdot \mathrm{mol}^{-1}\right)$ & $\ln A,\left(\mathrm{~min}^{-1}\right)$ & $R^{2}$ & $E_{\varphi}\left(\mathrm{kJ} \cdot \mathrm{mol}^{-1}\right)$ & $\ln A,\left(\mathrm{~min}^{-1}\right)$ & $R^{2}$ & $E_{\varphi}\left(\mathrm{kJ} \cdot \mathrm{mol}^{-1}\right)$ & $\ln A,\left(\mathrm{~min}^{-1}\right)$ & $R^{2}$ \\
\hline 0.1 & 130.2 & 29.4 & 0.9835 & 123.9 & 24.1 & 0.9966 & 135.6 & 31.1 \\
0.2 & 137.4 & 31.8 & 0.9830 & 127.2 & 26.3 & 0.9921 & 138.4 & 32.5 \\
0.3 & 137.9 & 32.0 & 0.9962 & 128.6 & 27.3 & 0.9938 & 145.6 & 34.9 & 0.9773 \\
0.4 & 139.2 & 32.5 & 0.9949 & 132.3 & 28.9 & 0.9939 & 147.3 & 35.7 & 0.9897 \\
0.5 & 142.6 & 33.7 & 0.9889 & 132.3 & 29.2 & 0.9924 & 147.9 & 36.2 \\
0.6 & 143.6 & 34.0 & 0.9930 & 135.9 & 30.5 & 0.9967 & 147.5 & 36.4 \\
0.7 & 136.8 & 32.0 & 0.9854 & 137.5 & 31.1 & 0.9858 & 145.5 & 0.9883 \\
0.8 & 136.6 & 31.9 & 0.9868 & 128.7 & 28.6 & 0.9885 & 145.3 & 36.1 \\
0.9 & 131.2 & 30.2 & 0.9831 & 121.4 & 26.6 & 0.9941 & 142.0 & 0.9900 \\
Mean & $\mathbf{1 3 7 . 3}$ & 31.9 & & $\mathbf{1 2 9 . 7}$ & $\mathbf{2 8 . 0}$ & & $\mathbf{1 4 3 . 9}$ & 36.2 & 0.9857 \\
\hline
\end{tabular}

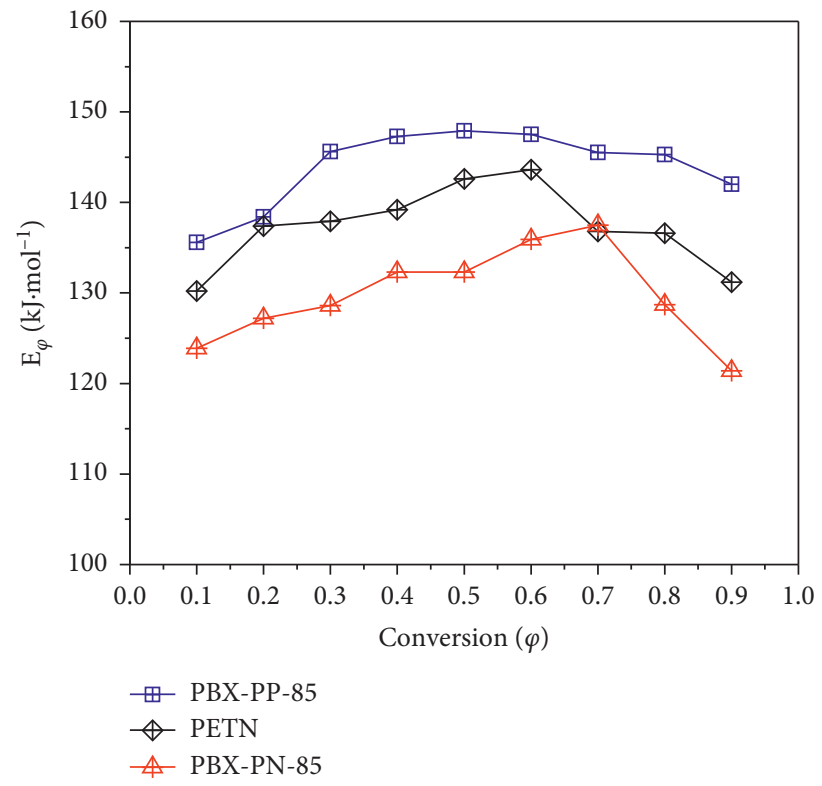

FIGURE 6: The dependence of activation energy on the conversion using the VST technique.

TABLE 6: Kinetic parameters of PETN and PBXs calculated from the model-fitting method.

\begin{tabular}{|c|c|c|c|c|c|c|c|c|c|}
\hline \multirow{2}{*}{ Model } & \multicolumn{3}{|c|}{ PETN } & \multicolumn{3}{|c|}{ PBX-PN-85 } & \multicolumn{3}{|c|}{ PBX-PP-85 } \\
\hline & $E_{\varphi}\left(\mathrm{kJ} \mathrm{mol}{ }^{-1}\right)$ & $\ln A,\left(\min ^{-1}\right)$ & $R^{2}$ & $E_{\varphi}\left(\mathrm{kJ} \mathrm{mol}{ }^{-1}\right)$ & $\ln A,\left(\min ^{-1}\right)$ & $R^{2}$ & $E_{\varphi}\left(\mathrm{kJ} \mathrm{mol}{ }^{-1}\right)$ & $\ln A,\left(\min ^{-1}\right)$ & $R^{2}$ \\
\hline 1 & 137.4 & 32.4 & 0.9818 & 122.0 & 27.6 & 0.9828 & 144.4 & 34.6 & 0.9896 \\
\hline 2 & 138.5 & 32.5 & 0.9815 & 121.6 & 27.2 & 0.9830 & 144.5 & 34.4 & 0.9896 \\
\hline 3 & 138.3 & 32.3 & 0.9827 & 121.9 & 27.1 & 0.9821 & 144.5 & 34.0 & 0.9892 \\
\hline 4 & 139.1 & 33.6 & 0.9900 & 123.5 & 28.7 & 0.9846 & 146.4 & 35.8 & 0.9908 \\
\hline 5 & 138.5 & 33.0 & 0.9890 & 122.8 & 28.2 & 0.9833 & 146.2 & 35.4 & 0.9907 \\
\hline 6 & 134.1 & 31.4 & 0.9845 & 122.9 & 27.9 & 0.9838 & 146.1 & 35.1 & 0.9904 \\
\hline 7 & 139.4 & 33.0 & 0.9838 & 123.9 & 28.3 & 0.9853 & 146.9 & 35.3 & 0.9906 \\
\hline 8 & 139.1 & 32.7 & 0.9935 & 123.9 & 28.1 & 0.9844 & 146.9 & 35.1 & 0.9908 \\
\hline 9 & 139.4 & 32.3 & 0.9862 & 123.7 & 28.5 & 0.9862 & 147.6 & 35.8 & 0.9905 \\
\hline 10 & 139.8 & 33.3 & 0.9754 & 119.7 & 27.2 & 0.9855 & 146.7 & 35.2 & 0.9886 \\
\hline 11 & 140.6 & 32.6 & 0.9860 & 125.6 & 28.0 & 0.9918 & 148.5 & 34.9 & 0.9913 \\
\hline 12 & 139.7 & 34.4 & 0.9853 & 124.9 & 29.8 & 0.9853 & 148.2 & 36.6 & 0.9914 \\
\hline 13 & 141.3 & 36.2 & 0.9846 & 124.8 & 31.1 & 0.9846 & 150.6 & 36.9 & 0.9940 \\
\hline 14 & 142.6 & 38.2 & 0.9834 & 129.6 & 34.2 & 0.9834 & 152.4 & 40.0 & 0.9903 \\
\hline
\end{tabular}


TABLE 7: Kinetic parameters of PETN and PBXs obtained by several methods.

\begin{tabular}{lccccc}
\hline & \multicolumn{2}{c}{ TG/DTG using KAS method } & \multicolumn{2}{c}{ Vacuum stability test (VST) } \\
Sample & \multicolumn{2}{c}{$\begin{array}{c}\text { Isoconversional method } \\
\text { In } A\left(\mathrm{~min}^{-1}\right)\end{array}$} & $\begin{array}{c}E_{\varphi} \\
\left(\mathrm{kJ} \cdot \mathrm{mol}^{-1}\right)\end{array}$ & $\begin{array}{c}\ln A \\
\left(\mathrm{~min}^{-1}\right)\end{array}$ & $\begin{array}{c}\text { Model-fitting method } \\
E_{\varphi}\left(\mathrm{kJ} \cdot \mathrm{mol}^{-1}\right)\end{array}$ \\
\hline PETN & 144.9 & 137.3 & 31.9 & 139.1 & 32.7 \\
PBX-PN-85 & 137.1 & 28.6 & 129.7 & 28.0 & 125.6 \\
PBX-PP-85 & 152.4 & 25.2 & 143.9 & 35.0 & 150.6 \\
\hline
\end{tabular}

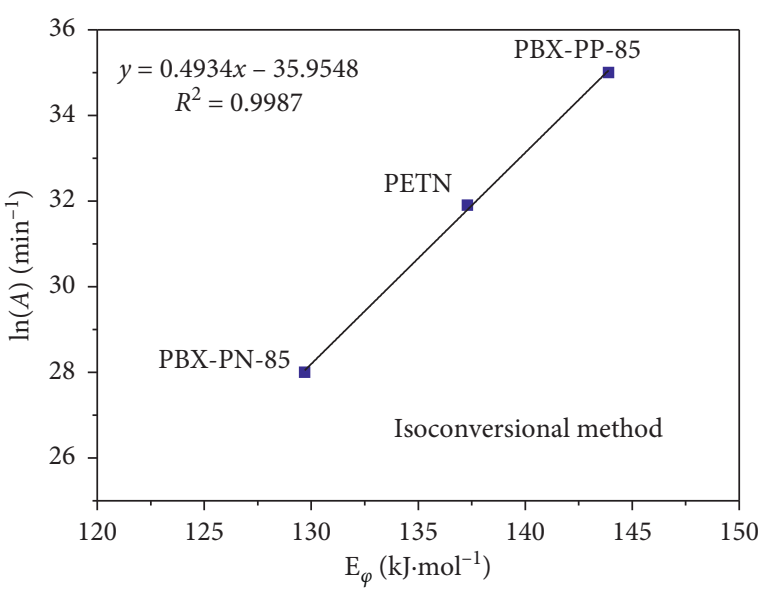

(a)

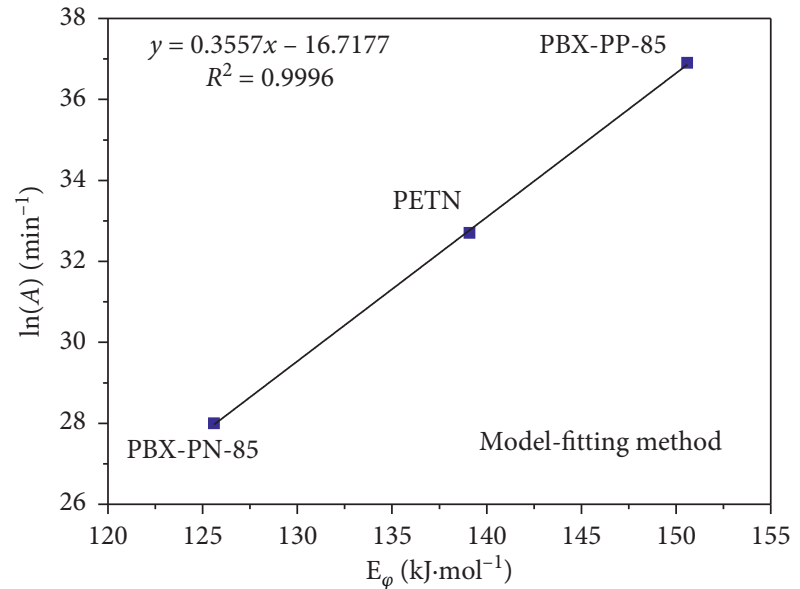

(b)

Figure 7: The linear dependence of $E_{\varphi}$ with $\ln A$ of all samples obtained from the VST test.

comparison, kinetic parameters obtained by different methods are presented in Table 7.

The values in Table 7 demonstrate the role of the binder on the initiation activation energy of PETN. The energetic binder based on NC reduces the activation energy (i.e., PBXPN-85 has lower thermal stability than that of PETN), while the introduction of the nonenergetic material based on PS increases the activation energy of the explosive.

The ranges of $E_{\varphi}$ values obtained by different methods were 125.6-137.1 kJ·mol ${ }^{-1}$ for PBX-PN-85, 137.3-144.9 kJ.mol ${ }^{-1}$ for PETN, and 143.9-152.4 kJ.mol ${ }^{-1}$ for PBX-PP-85. These ranges are narrow, proving the equivalence of these methods with each other. It is also noteworthy that $E_{\varphi}$ of PETN obtained in this work is in good agreement with that reported by Pouretedal et al. [15] $\left(135.1-136.9 \mathrm{~kJ} \cdot \mathrm{mol}^{-1}\right)$ and by Künzel et al. [16] $\left(137.4 \pm 3.4 \mathrm{~kJ} \cdot \mathrm{mol}^{-1}\right)$.

According to Brill et al. [35], the $E_{\varphi}$ and $\ln A$ values-determined from isothermal techniques in the same conditions-usually compensate each other. They found that all of $E_{\varphi}-\ln A$ pairs that lie in the regression line represent legitimate measurement and reliable results. We have plotted all $E_{\varphi}$ values of PETN, PBX-PN-85, and PBX-PP-85 versus corresponding $\ln \quad A$ values (presented in Table 7) in Figure 7.

It can be observed the linear relationship of $E_{\varphi}$ with $\ln A$ values, which confirm the accuracy of the kinetic parameters obtained by the isoconversional method and model-fitting method using the VST test.

\section{Conclusions}

The thermal decomposition behavior and kinetics of PETN, PBX-PN-85 (85\% PETN, 15\% NC-based binder), and PBXPP-85 (85\% PETN, 15\% PS-based binder) were examined by TG/DTG and VST techniques using model-fitting and isoconversional methods. The activation energy values computed by the non-isothermal technique (modified KAS method) were close to those calculated by model-fitting and isothermal isoconversional methods, ranging from $125.6-137.1 \mathrm{~kJ} \cdot \mathrm{mol}^{-1}$ for PBX-PN-85, $137.3-144.9 \mathrm{~kJ} \cdot \mathrm{mol}^{-1}$ for PETN, and $143.9-152.4 \mathrm{~kJ} \cdot \mathrm{mol}^{-1}$ for PBX-PP-85. The results indicate that the NC-based binder accelerates the thermal decomposition of $\mathrm{PBX}$, thus reducing the activation energy of single PETN. One more valuable conclusion of this study is the influence of the PS-based binder. Specifically, the presence of the PS-based binder causes no adverse effect on the thermal stability of the main explosive in PBX composition.

\section{Data Availability}

The data used to support the findings of this study are included in the article.

\section{Conflicts of Interest}

The authors declare that they have no conflicts of interest. 


\section{Acknowledgments}

DVT gratefully acknowledges the support of Vietnam $\mathrm{Na}$ tional Foundation for Science and Technology Development (NAFOSTED) under grant no. 107.02-2018.30.

\section{References}

[1] J. P. Agrawal, High Energy Materials: Propellants, Explosives and Pyrotechnics, John Wiley \& Sons, Hoboken, NJ, USA, 2010.

[2] T. Urbanski, Chemistry and Technology of Explosives, vol. 2, Pergamon Press, New York, NY, USA, 1965.

[3] A. Elbeih, J. Pachman, S. Zeman, and Z. Akstein, "Replacement of PETN by bicyclo-HMX in semtex 10. Problem of mechatronic," Armament, Aviation, Safety Engineering, vol. 1, pp. 7-16, 2010.

[4] H.-S. Kim and B.-S. Park, "Characteristics of the insensitive pressed plastic bonded explosive, DXD-59," Propellants, Explosives, Pyrotechnics, vol. 24, no. 4, pp. 217-220, 1999.

[5] S. Moore, M. Schantz, and W. MacCrehan, "Characterization of three types of semtex (H, 1A, and 10)," Propellants, Explosives, Pyrotechnics, vol. 35, no. 6, pp. 540-549, 2010.

[6] A. Elbeih, S. Zeman, M. Jungova, and Z. Akstein, "Effect of different polymeric matrices on the sensitivity and performance of interesting cyclic nitramines," Central European Journal of Energetic Materials, vol. 9, no. 2, pp. 131-138, 2012.

[7] A. Elbeih, S. Zeman, and J. Pachman, "Effect of polar plasticizers on the characteristics of selected cyclic nitramines," Central European Journal of Energetic Materials, vol. 10, no. 3, pp. 339-350, 2013.

[8] N. T. Toan, P. D. Nhan, and V. H. Phuong, "Thermal decomposition and shelf-life of PETN and PBX based on PETN using thermal methods," Vietnam Journal of Science and Technology, vol. 56, no. 3, pp. 303-311, 2018.

[9] A. Elbeih, M. M. Mohamed, and T. Wafy, "Sensitivity and detonation characteristics of selected nitramines bonded by sylgard binder," Propellants, Explosives, Pyrotechnics, vol. 41, no. 6, pp. 1044-1049, 2016.

[10] B. Vogelsanger, "Chemical stability, compatibility and shelf life of explosives," CHIMIA International Journal for Chemistry, vol. 58, no. 6, pp. 401-408, 2004.

[11] Q.-L. Yan, S. Zeman, and A. Elbeih, "Recent advances in thermal analysis and stability evaluation of insensitive plastic bonded explosives (PBXs)," Thermochimica Acta, vol. 537, pp. 1-12, 2012.

[12] Q.-L. Yan, S. Zeman, P. E. Sánchez Jiménez, F.-Q. Zhao, L. A. Pérez-Maqueda, and J. Málek, "The effect of polymer matrices on the thermal hazard properties of RDX-based PBXs by using model-free and combined kinetic analysis," Journal of Hazardous Materials, vol. 271, pp. 185-195, 2014.

[13] M. Abd-Elghany, A. Elbeih, and S. Hassanein, "Thermal behavior and decomposition kinetics of RDX and RDX/HTPB composition using various techniques and methods," Central European Journal of Energetic Materials, vol. 13, no. 3, pp. 714-735, 2016.

[14] T. Nguyen, D. Phan, D. Nguyen, V. Do, and L. Bach, "The chemical compatibility and adhesion of energetic materials with several polymers and binders: an experimental study," Polymers, vol. 10, no. 12, p. 1396, 2018.

[15] H. R. Pouretedal, S. Damiri, M. Ravanbod, M. Haghdost, and S. Masoudi, "The kinetic of thermal decomposition of PETN, Pentastite and Pentolite by TG/DTA non-isothermal methods," Journal of Thermal Analysis and Calorimetry, vol. 129, no. 1, pp. 521-529, 2017.

[16] M. Künzel, Q.-L. Yan, J. Šelešovský, S. Zeman, and R. Matyáš, "Thermal behavior and decomposition kinetics of ETN and its mixtures with PETN and RDX," Journal of Thermal Analysis and Calorimetry, vol. 115, no. 1, pp. 289-299, 2013.

[17] K.-S. Jaw and J.-S. Lee, "Thermal behaviors of PETN base polymer bonded explosives," Journal of Thermal Analysis and Calorimetry, vol. 93, no. 3, pp. 953-957, 2008.

[18] C.-C. Huang, M.-D. Ger, and S.-I. Chen, "Study on thermal decomposition of Pentolites by modified vacuum stability apparatus and differential scanning calorimetry," Propellants, Explosives, Pyrotechnics, vol. 17, no. 5, pp. 254-259, 1992.

[19] S. K. Bhattacharia, J. Nunley, and B. L. Weeks, "New insights into kinetics of PETN decomposition from the product and reactant point of view: an investigation with mass spectrometry and differential scanning calorimetry," Thermochimica Acta, vol. 617, pp. 38-43, 2015.

[20] W. P. C. De Klerk, M. A. Schrader, and A. C. Van der Steen, "Compatibility testing of energetic materials, which technique?" Journal of Thermal Analysis and Calorimetry, vol. 56, no. 3, pp. 1123-1131, 1999.

[21] S. Vyazovkin, A. K. Burnham, J. M. Criado, L. A. PérezMaqueda, C. Popescu, and N. Sbirrazzuoli, "ICTAC kinetics committee recommendations for performing kinetic computations on thermal analysis data," Thermochimica Acta, vol. 520, no. 1-2, pp. 1-19, 2011.

[22] S. Vyazovkin and C. A. Wight, "Isothermal and non-isothermal kinetics of thermally stimulated reactions of solids," International Reviews in Physical Chemistry, vol. 17, no. 3, pp. 407-433, 1998.

[23] Q.-L. Yan, S. Zeman, F.-Q. Zhao, and A. Elbeih, "Nonisothermal analysis of $\mathrm{C} 4$ bonded explosives containing different cyclic nitramines," Thermochimica Acta, vol. 556, pp. 6-12, 2013.

[24] A. Elbeih, M. Abd-Elghany, and T. Elshenawy, "Application of vacuum stability test to determine thermal decomposition kinetics of nitramines bonded by polyurethane matrix," Acta Astronautica, vol. 132, pp. 124-130, 2017.

[25] A. Singh, G. Kaur, C. Sarkar, and N. Mukherjee, "Investigations on chemical, thermal decomposition behavior, kinetics, reaction mechanism and thermodynamic properties of aged TATB," Central European Journal of Energetic Materials, vol. 15, no. 2, pp. 258-282, 2018.

[26] H. E. Kissinger, "Variation of peak temperature with heating rate in differential thermal analysis," Journal of Research of the National Bureau of Standards, vol. 57, no. 4, pp. 217-221, 1956.

[27] G. I. Senum and R. T. Yang, "Rational approximations of the integral of the Arrhenius function," Journal of Thermal Analysis, vol. 11, no. 3, pp. 445-447, 1977.

[28] V. Georgieva, D. Zvezdova, and L. Vlaev, "Non-isothermal kinetics of thermal degradation of chitosan," Chemistry Central Journal, vol. 6, no. 1, p. 81, 2012.

[29] Q.-L. Yan, S. Zeman, and A. Elbeih, "Thermal behavior and decomposition kinetics of Viton A bonded explosives containing attractive cyclic nitramines," Thermochimica Acta, vol. 562, pp. 56-64, 2013.

[30] Q.-L. Yan, S. Zeman, J. Š mand/Cro, R. Svoboda, and A. Elbeih, "Thermal behavior and decomposition kinetics of Formex-bonded explosives containing different cyclic nitramines," Journal of Thermal Analysis and Calorimetry, vol. 111, no. 2, pp. 1419-1430, 2012. 
[31] ASTM-E-698-11, Standard Test Method for Arrhenius Kinetic Constants for Thermally Unstable Materials, American Society for Testing and Materials Philadelphia, Philadelphia, PA, USA, 1979.

[32] J. Kimura, "Chemiluminescence study on thermal decomposition of nitrate esters (PETN and NC)," Propellants, Explosives, Pyrotechnics, vol. 14, no. 3, pp. 89-92, 1989.

[33] C.-C. Huang, M.-D. Ger, Y.-C. Lin, and Sun-IChen, "Thermal decomposition of mixtures containing nitrocellulose and pentaerythritol tetranitrate," Thermochimica Acta, vol. 208, pp. 147-160, 1992.

[34] N. P. Loginov and S. N. Surkova, "Effectiveness of the action of stabilizers in explosive compositions under mechanical loading," Combustion, Explosion, and Shock Waves, vol. 42, no. 1, p. 100, 2006

[35] T. B. Brill, P. E. Gongwer, and G. K. Williams, "Thermal decomposition of energetic materials. 66. Kinetic compensation effects in HMX, RDX, and NTO," The Journal of Physical Chemistry, vol. 98, no. 47, pp. 12242-12247, 1994. 